\title{
Investigation of Power Quality In Health Care Facility
}

\author{
Rusdy Hartungi ${ }^{1}$, Liben Jiang ${ }^{2}$ \\ ${ }^{1,2}$ School of Built and Natural Environment \\ University of Central Lancashire \\ Preston PR1 2HE, Lancashire, UK \\ Phone/Fax number: +0044 17723741, e-mail: RHartungi@uclan.ac.uk
}

\begin{abstract}
Modern healthcare facility has unique power system requirements as the power quality and reliability is a crucial feature to maintain the critical services such as surgical operations, intensive care units and other critical services. Healthcare facility has become dependent on the quality of electrical supply. This paper aims at assessing the level of harmonic pollution to a health care facility. The investigation focus on assessing the level of THD on this healthcare facilitates. Further discussion includes various ways of reducing harmonics in health care facilities from the study it was found that although there are numerous amount of harmonics producing equipments exist, the total harmonics distortion is still within the recommended level as advise by IEEE 519. There is also clear evidence that active filter using active harmonics conditioner play an important role to this instance.
\end{abstract}

\section{Keywords}

Power Quality, Harmonics, THD, Healthcare facility

\section{Background and Introduction}

The power quality has emerged as one of a central issue in the electrical supply and distribution in a built environment as a poor power quality might cause various problems. Depending on how severe the quality have been distorted or what sort of equipments/appliances are affected, the consequence of the poor power quality and power quality distortion may range from a minor nuisance trip, loss of critical data, extensive equipment damage to lost of life.

As far as power quality is concerned, there are various definitions of power quality that has been used throughout literatures and practices, but in general many agree that the power quality concern with any power problems manifested in voltage and current or frequency deviations that result in failure or disoperation of customer equipment $[10,12]$

In health care facility, one of the most contentious issues in the power quality is harmonics problems which typically exist in significant quantities as a result of the proliferation of state of the art of modern biomedical equipments. Harmonics have become a greater concern as nowadays there are a wide range of biomedical equipments which draw high impact current and power and then inject back the non-sinusoidal current to the electrical supply systems. Among those kind of equipments are Magnetic Resonance Imaging (MRI), Nuclear Magnetic Resonance Imaging (NMRI), Ultra Sound Machine, Computerised-Axial Tomography (CT) scan, Laser surgery equipment, X-ray machines, Gamma Camera, etc. In addition to the harmonics pollution from biomedical equipment there is also great harmonics coming from IT/Data support system, UPS, Lighting and Lighting Control Systems (e.g. HID, HF control gear), some of HVAC systems as well as Variable Speed Drives (VSD) for vertical/horizontal transportation

The harmonics on the electrical supply system of a health care facility need more attention in comparison to any other sectors in construction industries as the supply system is also used to supply the services critical to survival such as surgical operations, intensive care units (ICU), etc.

Currently, there has been various damaging impact of the harmonic pollution on the facility and equipments that has been reported. The impact varies from the power cut of the emergency supply system caused by inadvertent operation of the under voltage or over voltage relays to the impact on the biomedical equipment itself.

Depending upon the type of disturbance which impact on under or over voltage relays, its duration, and the immunity of the equipment to that disturbance, gradual or fast occurring damage to electrical and electronic components may result. A disturbance such as a voltage surge entering the AC power input of biomedical equipment may not be sufficiently mitigated by internal overvoltage and over current protection devices and may propagate through the power supply to other sensitive electronic subsystems and components.

It has been reported that the harmonics on biomedical equipment might cause several problems. The harmonic 
pollution may result the equipment to read voltage levels incorrectly resulting in incorrect data processing (ones being read like zeros) or stored data [1.3]. Incorrect diagnostic data processing and storage due to poor power quality might alter the control parameters stored in electronic biomedical equipment that has used to diagnose a patient's condition will result a misreporting of the patient's health condition. For instance, the status of a CT system may be misreported via the digital readout. Biomedical equipment such as blood-pressure monitors may display diagnostic data, such as a digital readout or level indicator that disagrees with the patient's prevailing condition. A series of disturbances occurring over the period of a few hours or a few months, for example, may chip away at internal protection devices and electronic components of biomedical equipments, although damage to equipment may be virtually unnoticeable, but intermittent equipment malfunctions may be noticeable until eventual failure occurs on equipments.

Other harmonics effect might include the malfunctions in biomedical equipment such as distortion of displays due to distorted voltage, altered data [2.4], equipment lockup, control/alarm and malfunction due to Microprocessor malfunction [2, 3]. The effect of harmonics to external environment should also be taken into consideration as excessive Electromagnetic Compatibility (EMC) effects of harmonics' disturbance upon healthcare equipment might cause disturbance and interference to telecommunications systems.

This study investigates the power quality issue in health care facility with main emphasis on harmonics.

\section{Aims and Objectives}

This paper aims at assessing the level of harmonic pollution in a health care facility in term of harmonic distortion. It is also intended to see how effective an active filter might work to reduce the level of harmonic distortion. Further discussion includes various ways of reducing harmonics in health care facilities.

\section{Theoretical Framework}

An important measure in addressing harmonic problems is in defining limits to total harmonic voltage and current distortion [7, 8]. Total Harmonic Distortion (THD) is a useful measure as it can help to predict whether a system is likely to experience problems as a result of the harmonic distortion. Total harmonic distortion of voltage $T H D_{V}$ or current $T H D_{\mathrm{i}}$ is generally expressed as a ratio or percentage of the fundamental of voltage or current.

So the total harmonics distortion of voltage $T H D_{v}$

$$
T H D_{v}=\frac{\sqrt{\sum_{k=2}^{\infty} V_{k}^{2}}}{V_{1}}
$$

While the total harmonics distortion of current $T H D_{i}$ is

$$
T H D_{i}=\frac{\sqrt{\sum_{k=2}^{\infty} I_{k}^{2}}}{I_{1}}
$$

$I_{k}$ and $V_{k}$ are the currents and voltage at their respective harmonics. $I_{1}$ and $V_{1}$ is the fundamental value of current and voltage.

For harmonic limits, IEC and IEEE use two principally different approaches. The IEC standards set limits to the amount of emission of individual equipment, whereas the IEEE harmonic standard limits the emission per customer. Under the IEEE standard the responsibility lies with the customer who may decide to install filters instead of buying better equipment. Under the IEC standards the responsibility lies with the manufacturers of polluting equipment. The difference can be traced back to the aim of the documents: the IEEE standard aimed at regulating the connection of large industrial customers, whereas the IEC document mainly aims at small customers that do not have the means to choose between mitigation options. The IEEE 519-1992 Recommended Practices and Requirements for Harmonic Control in Electrical Power Systems [6] provides guidelines from determining what acceptable limits are. The harmonic limits for current depend on the ratio of Short Circuit Current (SCC) at PCC (or how stiff it is) to average Load Current of maximum demand over 1 year. For voltage harmonics, the voltage level of the system is used to determine the limits, as shown in Table 1 . At the higher voltages, more customers will be affected, hence, the lower limits.

Table 1. - Voltage Harmonic Limits as per IEEE 519-1992

\begin{tabular}{|l|l|}
\hline Bus Voltage & $\begin{array}{l}\text { Voltage Harmonic Limit } \\
\text { as \% of Fundamental }\end{array}$ \\
\hline$\leq 69 \mathrm{KV}$ & $\begin{array}{l}\text { Individual harmonic }= \\
3.0 \%, T H D_{v}=5.0 \%\end{array}$ \\
\hline$\geq 161 \mathrm{KV}$ & $\begin{array}{l}\text { Individual harmonic }= \\
1.0 \%, T H D_{v}=1.0 \%\end{array}$ \\
\hline
\end{tabular}

For low voltage LV system IEEE 519-1992 has set up $T H D_{V}=3 \%$ for Hospitals and Airports.

\section{Brief Description of The Facility}

Opened December 2007 in England, the health care facility in this case was claimed as one of the largest of its type in Europe, at that time. It is a nine stories newly built specialist cancer centre covering the area of $65,000 \mathrm{~m} 2$. It not only serves the major cancer treatment such as surgery, chemotherapy, radiotherapy, genetherapy, immunotherapy and hormone therapy, but also serve a small amount of complimentary treatments. 
As shown on the schematic Figure A.1, the incoming MV supply to site is $11 \mathrm{KV}$ system coming from an intake substation which is owned and operated by the trust. The normal system arrangement of MV system is open ring with the open point positioned such that no more than 2 transformers are supplied from a single feeder.

The main LV distributions comprise 3 main distribution boards designated as SBE01, SBE02 and SBE03. These boards are supplied from 3No of 1.750MVA air cooled $\mathrm{D} / \mathrm{y}$ transformers via a closed transition transfer switch. Each SBE01, SBE02 and SBE03 distribution boards also provide power supply to a number of VSD-lifts used for vertical transportation of patients, visitors as well as medical staffs. Various states of the arts of biomedical equipments which draw high current and power are also installed such as Gamma Cameras, MRI, CT scanner, and Ultra Sound Machines.

The standby supply system is provided by 3 No of 1.5 MVA standby generators. The standby system is also backed up by emergency supplies to critical systems by the provision of UPS.

SBE01, SBE02 and SBE03 have outgoing circuits of 61, 42 and 93 respectively. Each of SBE distribution board has its own set of PFC capacitor bank with integral Active Harmonic Conditioner (AHC) that could be switched $\mathrm{ON}$ and OFF. All main distribution boards SBE01, SBE02 and SBE03 have several outgoing circuits which are used to power various circuits throughout facilities.

\section{Experimental Design and Measurement}

A Fluke 434 Power Quality Analyser (PQA) fitted with i400s current clamps or i400s flexible AC current probes is used to observe the harmonics spectrum and the level of voltage and current total harmonics distortion, THDv and THDi. As the internal memory of the Fluke 434 PQA is limited, the PQA was linked to a laptop through an optical serial port to enable analysis and data capture directly to the hard drive.

Figure 1 shows an example of reading and observation of harmonics spectrums and total harmonics distortion that was conducted in this facility. Readings and observation were taken between March and April 2009, during normal working hours. Some of the test and investigation was started at 07:00 prior to the first patient treatment session.

Various points throughout the supply systems were tapped with clamp or probe for reading and observation purposes. But for the purpose of this paper, only the results of three major observation points will be reported and discussed which are all located in the incoming supplies of main distribution boards SBE01, SBE02 and SBE03.

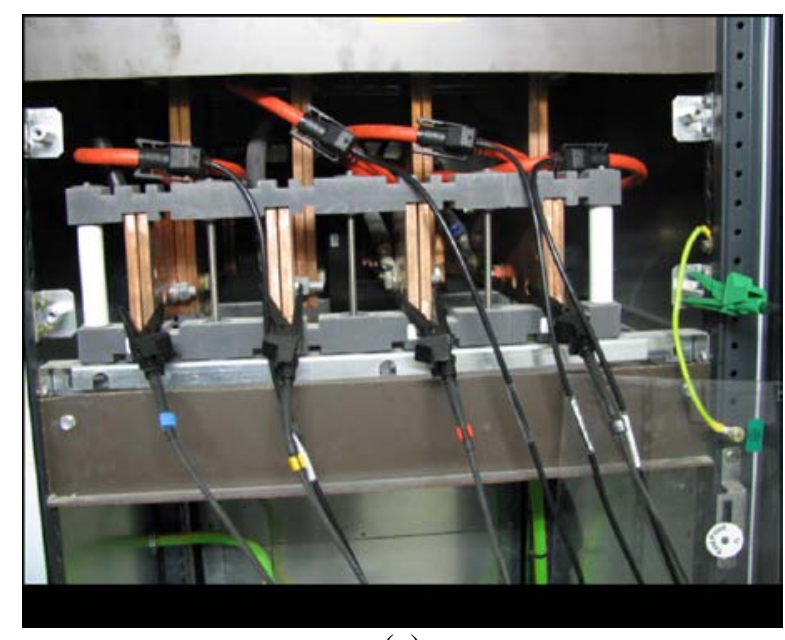

(a)

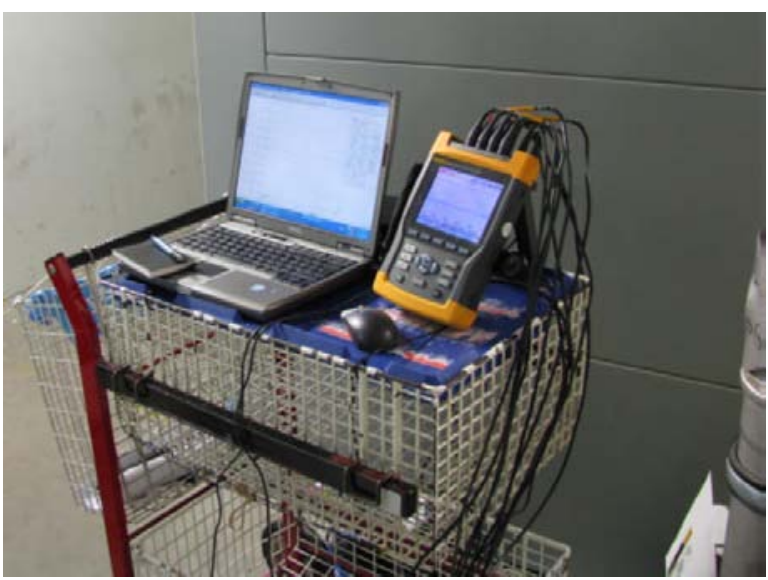

(b)

Figure 1: Example of Harmonics Observation and Reading during the observation period.

\section{Results and Findings}

As shown on Figure A.1, the SBE01 distribution board did not have significant voltage or current distortion, with the active harmonic conditioner on THDi was $7.1 \%$ and THDV was $1.6 \%$, active harmonic conditioner off the level were $11.8 \%$ and $1.9 \%$ respectively. These values correlated with the THDi readings on the control panel screen of the conditioner. The values were well below the levels recommended by IEEE 519-1992

Once the board incoming section (section A) was opened for inspection it became clear that it would not be possible to install the current clamps without significant personal risk to the engineer carrying out the work. The arrangement was different due to the inclusion of the two bus couplers in the SBE02 switchboard. Therefore no current information was available from SBE02 main incomer. The distribution board has had relatively high voltage distortion, L2 with the conditioner on was the lowest reading at $3.9 \%$ and the highest reading with the filter off was $5.5 \%$. The voltage distortion was mainly caused by the $6 n+/-1$ harmonic current. 
On SBE03 the board had $T H D_{i}$ of $19.5 \%$ with the filter on and $9.2 \%$ with the filter off, $T H D_{v}$ was $1.8 \%$ and $2.5 \%$ in case the AHC is off. These values did not correlate with the control screen on the conditioner. It has been observed during this investigation and previously that the conditioners reduce the $T H D_{i}$ by approximately 5\%. The screen for this conditioner showed a $6 \%$ reduction for $L 1$ and $L 3$ and no reduction for $L 2$. The current waveform also became visibly more distorted when the conditioner was switched on. The values are below the planning standard in IEEE 519 (3\%) and so it would not be expected that disruption to the operation of the biomedical equipment would occur.

The harmonic spectrum for the three phases showed that the dominant harmonic was the 3rd which for $L 2$ was approximately $11 \%$. 5th and 7 th were at approximately $5 \%$. The neutral current, as expected, was dominated by the triple-N harmonics. The 3rd harmonic component was 5 times larger than the fundamental. As with SBE 01 the total RMS current (342A) is significantly below the total rating of the board (3600A) and so negative effects would not be expected.

\section{Discussion and Conclusion}

The present study demonstrates the importance of the power quality of electrical supply system supply of health care facilities. In spite of several existing recommendations and standards for testing medical electrical equipments, there is a lack of standard related to test cases considering the effects of high harmonic.

From the above test and measurement it seems that although the health facility contains a lot of non-linear load, it seems that the power quality still within the range as recommended in the IEEE standard. There is also clear evidence that Active filter using active harmonics conditioner work well in reducing the harmonics pollution in the health care facility. Although active harmonics conditioner might work well in such as the health care facility in this case, the power quality could still be further improved to reduce risks to the patients and to provide better health treatment.

Various methods for power quality improvement have been recommended as a result from previous research $[10,11,12]$. Apart from the above solution, there are still handful approaches to limit harmonic levels that have been reported on previous study. These range from reducing the harmonics generated by equipment to installing large filters in building wiring systems. Some approaches use passive filters or special transformers, while others use active current shaping circuits. Selection of a method suitable for a particular case becomes a complicated decision making process, the complication normally arises from the difficulty of predicting how a filter will perform and what side effects may be created in a specific system application. Passive filters might also be supplementary solution. Passive Filters can be applied to other equipments producing the significant harmonics, such as on the input of VSDs on Lifts. The filters are designed to block frequencies the drive generates to prevent them from being passed back into the electrical supply system. However there is still high risk of overload as well as the risk of introduction of new resonances that might exist.

Tackling harmonics by reducing the level of harmonics of at their source by limiting harmonics distortion from harmonics generating equipments has been argued as one of the most effective ways in reducing the level of harmonics pollution in general power systems [10, 12]. This might be a sound solution for health care facility as the health care equipment could be chosen as such that only equipment with the lowest level of harmonics distortion are installed. However, it is apparently that initial cost of acquiring such equipment might have become a barrier.

Other solution which might increase the immunity of the healthcare electrical supply systems to harmonics is from the improvement on supply transformer as well as from the conductors. De-rating of transformers or over sizing the transformers, giving a transformer an appropriate KFactor rating, as well as oversizing the neutral conductor to account for additional heating and load loss as a result of harmonics might be improve the immunity of the electrical power supply systems. However, the larger conductors to oversize transformers as well as neutral might be a barrier in implementing it and therefore might not necessarily be an economic solution.

Thus, harmonics existence in the electrical supply systems of health care facility is already evidence and always become part of the systems. However evidence also shows that there is various ways of mitigating it. Achieving the limits as stated in the standard could still be achieved.

\section{Acknowledgement}

The Authors want to thank to Mr John McKenna for conducting the measurements on site.

\section{References}

[1]. De Keulenaer, Hans, Power Quality \& Utilisation Guide, Leonardo Energy, 2006

[2]. Heriakian, Isabelle, Power quality critical sectors: Power Quality for healthcare facilities, Leonardo Energy, 2009.

[3]. Heriakian, Isabelle, Power quality critical sectors: Power Quality in hospital , Leonardo Energy, 2009

[4]. Ramos, MC Giacco and Tahan, CM Vieira, An Assessment of the Electric Power Quality and Electrical Installation Impacts on Medical Electrical Equipment Operations at Health Care Facilities. American Journal of Applied Sciences 6 (4): 638645, 2009ISSN 1546-9239

[5]. EN 50160:2007, Voltage characteristics of electricity supplied by public distribution networks. British Standard 
Institution (BSI) BS EN 50160 is the British Standard version of The European Standard EN 50160:2007

[6]. EN 61000-4-30-2003 Testing and measurement techniques - Power quality measurement methods. This is the EN version of IEC $61000-4-30$

[7]. EN 61000-3-2-2006 Electromagnetic compatibility (EMC) Part 3-2: Limits - Limits for harmonic current emissions (equipment input current $\leq 16 \mathrm{~A}$ per phase)

[8] IEEE 519-1992 Recommended Practices and Requirements for Harmonic Control in Electrical Power Systems

[9]. IEC 61000-4-7 Testing and measurement techniques, Section 7: General guide on harmonics and interharmonics measurements and instrumentation, for power supply systems and equipment connected thereto.

[10]. Key, T and 1. S. Lai, "Cost and Benefits of Harmonic Current Reduction for Switch-Mode Power Supplies in a Commercial Building," in Con! Rec. of IEEE lAS Annual. Mtg., Orlando, FL, Oct. 1995, pp. 1101-1108.

[11]. Lai, S. and T. S. Key, "Cost Effectiveness of Harmonic Mitigation Equipment for Commercial Office Buildings," IEEE lAS Annual Mtg., San Diego, CA, Oct. 1996.

[12]. Jovanovic, M.M and D. E. Crow, "Merits and Limitations of Full-Bridge Rectifier with LC Filter in Meeting IEC 1000-32 Harmonic-Limit Specifications," in Con! Rec. of Appl. Pwr Electr. Con!, Dallas, TX, Mar. 1991, pp. 415-422 

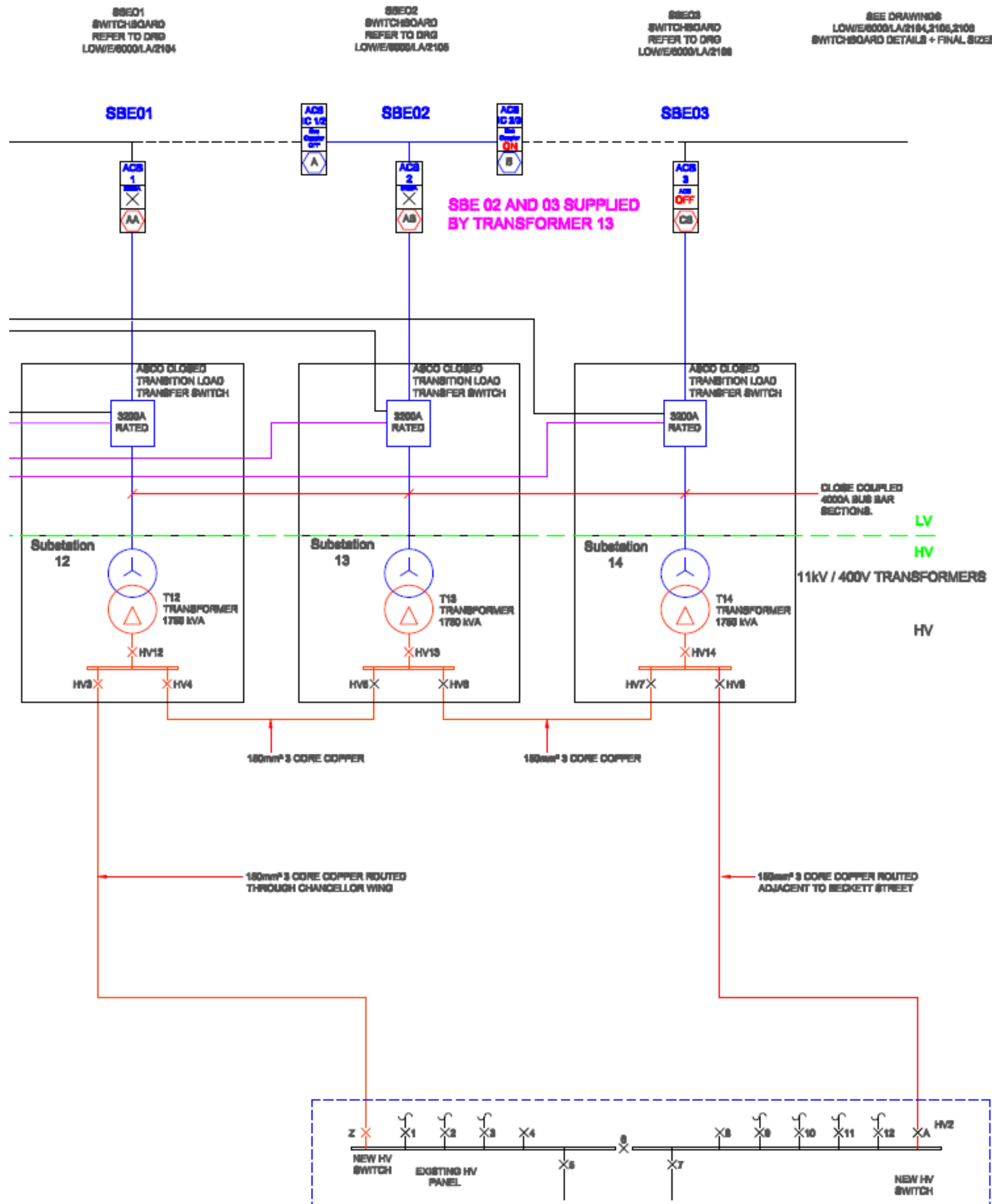

Trust Intake Substation

Adjacent to the WRVS tea bar in front of Lincoln Wing

Figure A.1. HV Schematic of the system Showing SBE01, SBE02, SBE03 


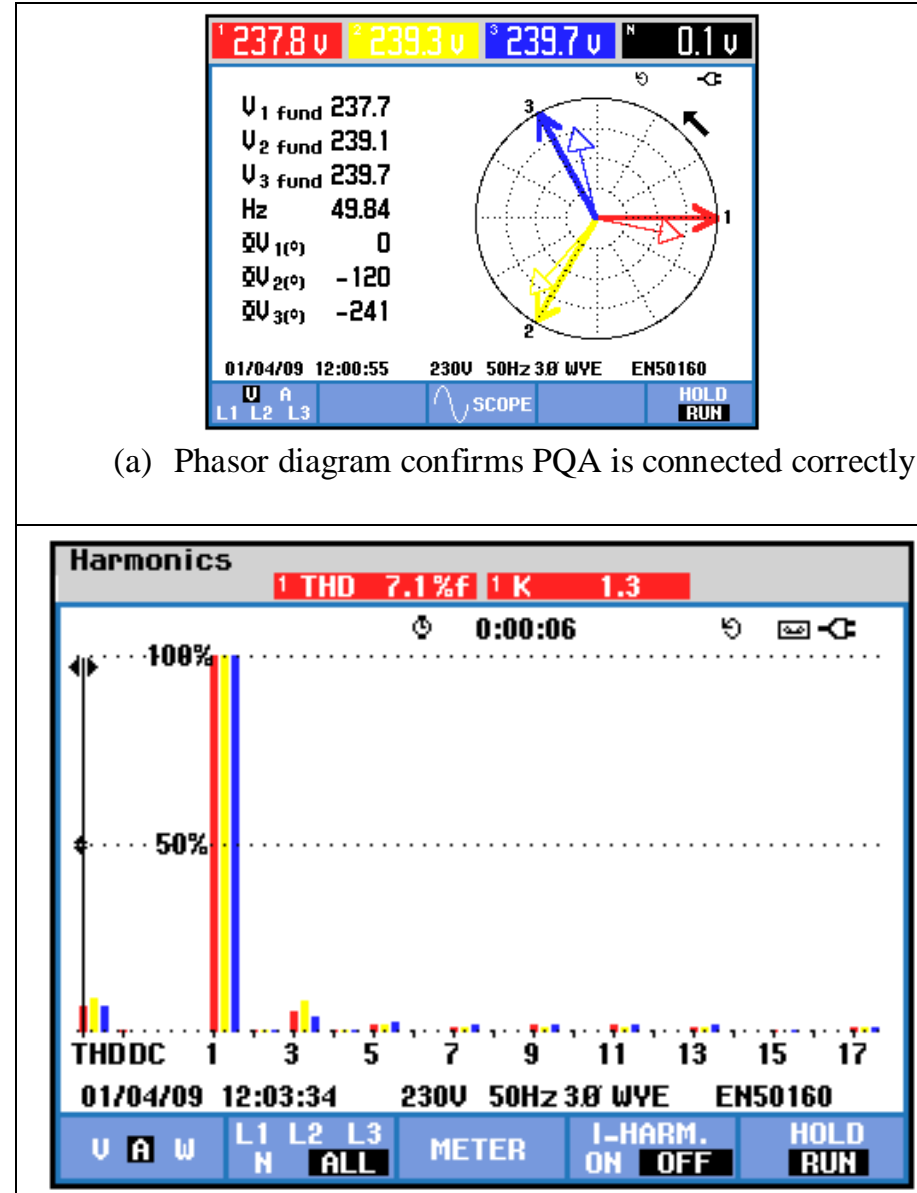

(c) $T H D_{i}=7.1 \%$ of the fundamental with the Active Harmonic Conditioner ON

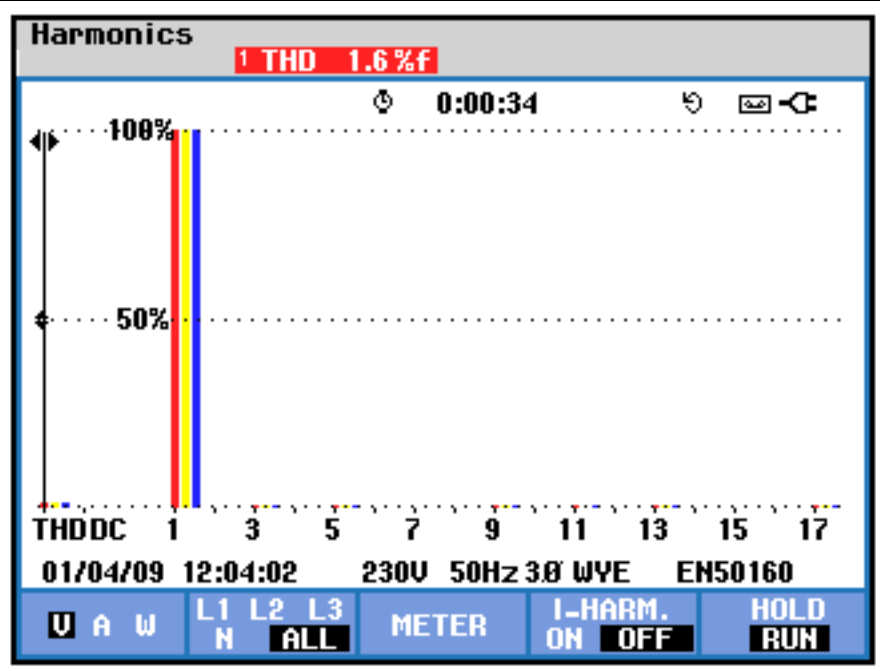

(e) $T H D_{v}=1.6 \%$ of the fundamental with the Active Harmonic Conditioner ON



(b) Simple View of PQA

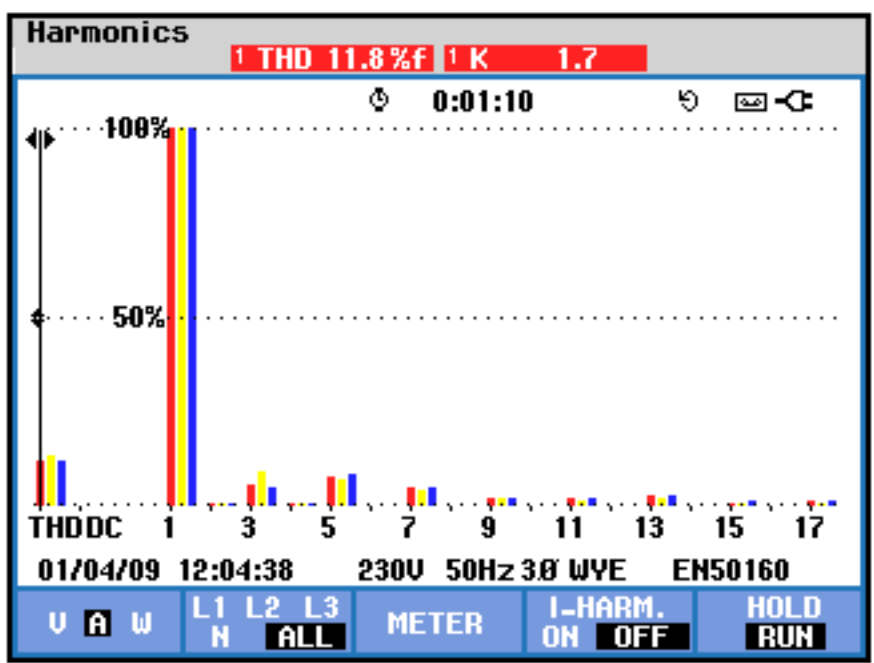

(d) $T H D_{i}=11.8 \%$ of the fundamental with the active harmonic conditioner OFF

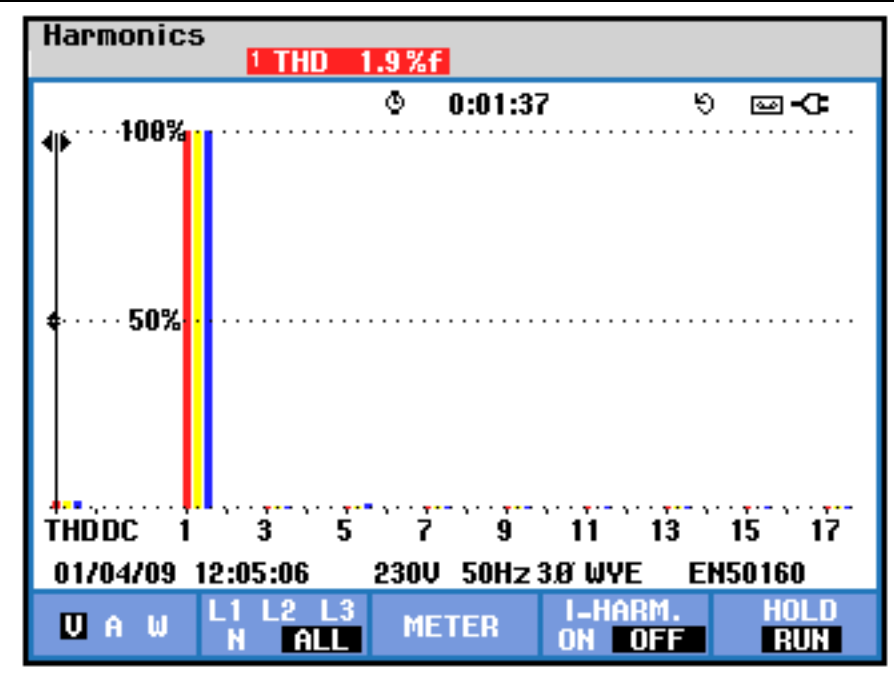

(f) $T H D_{v}=1.9 \%$ of the fundamental with the Active Harmonic Conditioner ON

Figure A.2: Result of $T H D_{i}$ and $T H D_{v}$ at SBE01 Incoming Supply with Active Harmonic Conditioner is ON and OFF 


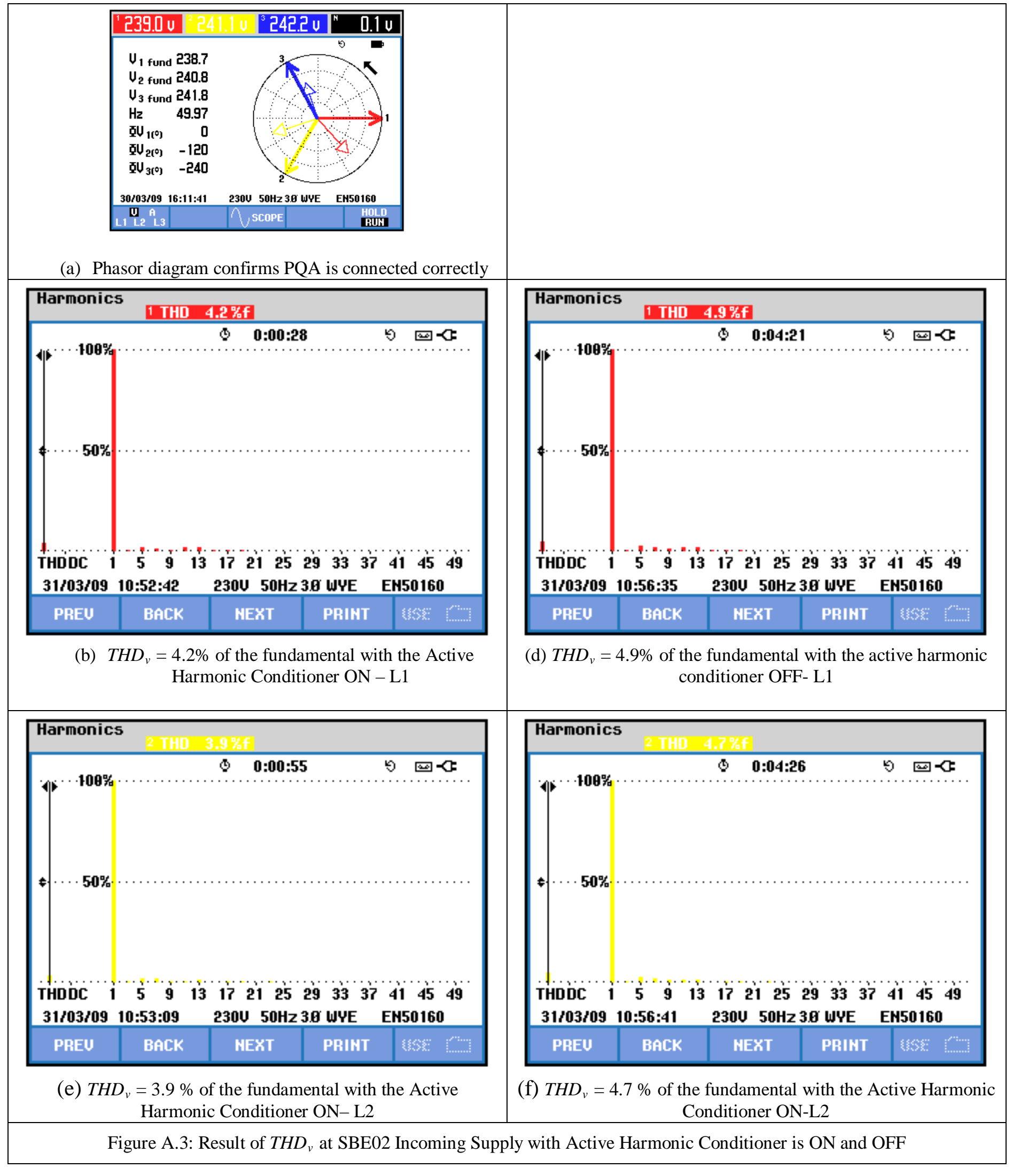




\begin{tabular}{|c|c|}
\hline \multirow{3}{*}{ 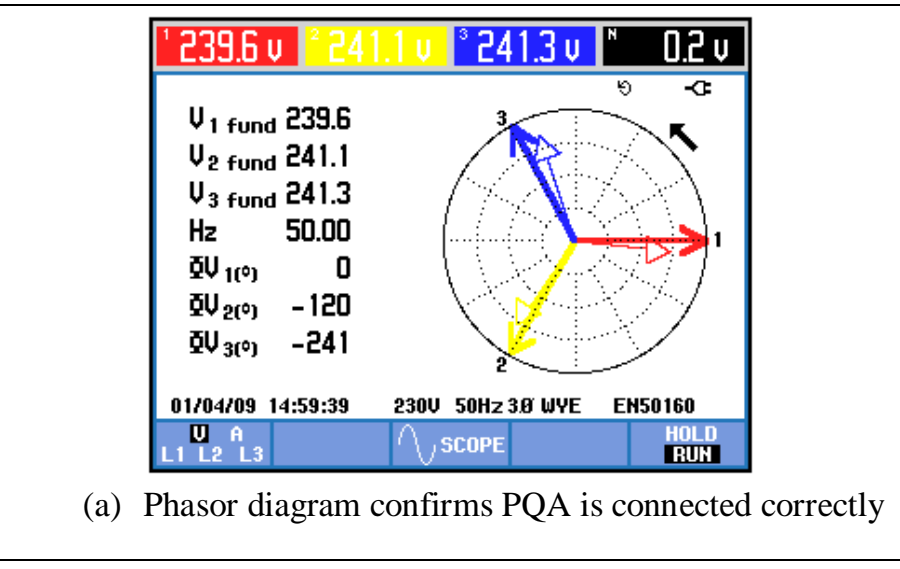 } & \multirow[b]{2}{*}{ 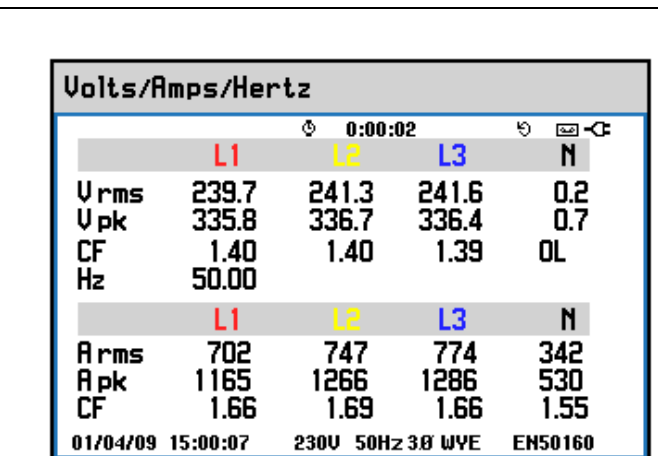 } \\
\hline & \\
\hline & $\begin{array}{l}\text { (b) Simple View of PQA } \\
\end{array}$ \\
\hline 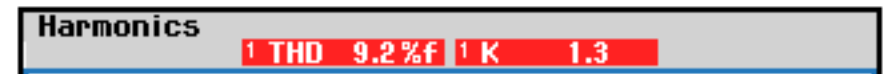 & \begin{tabular}{|lll} 
Harmonics & 1 THD $19.5 \%$ 盟 $1 \mathrm{~K}$ & 1.8 \\
\end{tabular} \\
\hline 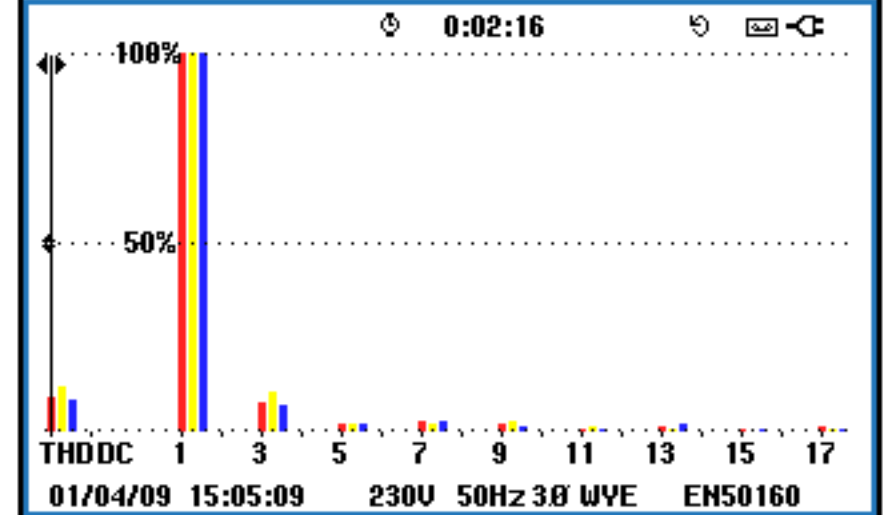 & $\left.\left.\right|_{\text {THDDC }} ^{01 / 04 / 09}\right|_{15: 03: 00}$ \\
\hline 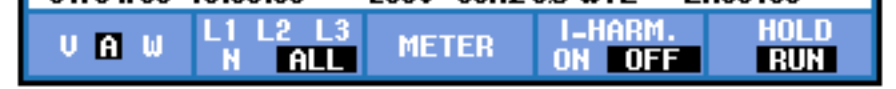 & 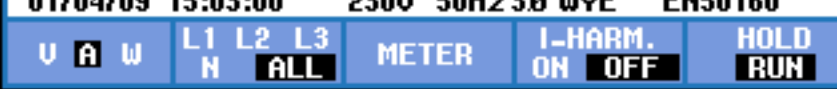 \\
\hline $\begin{array}{r}\text { (c) } T H D_{i}=7.1 \% \text { of the fundamental with the Active Harmonic } \\
\text { Conditioner ON }\end{array}$ & $\begin{aligned} & \text { (c) } T H D_{i}= 19.5 \% \text { of the fundamental with the active } \\
& \text { harmonic conditioner OFF }\end{aligned}$ \\
\hline \begin{tabular}{|ll} 
Harmonics & 1 THD $1.8 \% \mathrm{Ff}$
\end{tabular} & Harmonics 1 THD $2.5 \%$ \\
\hline 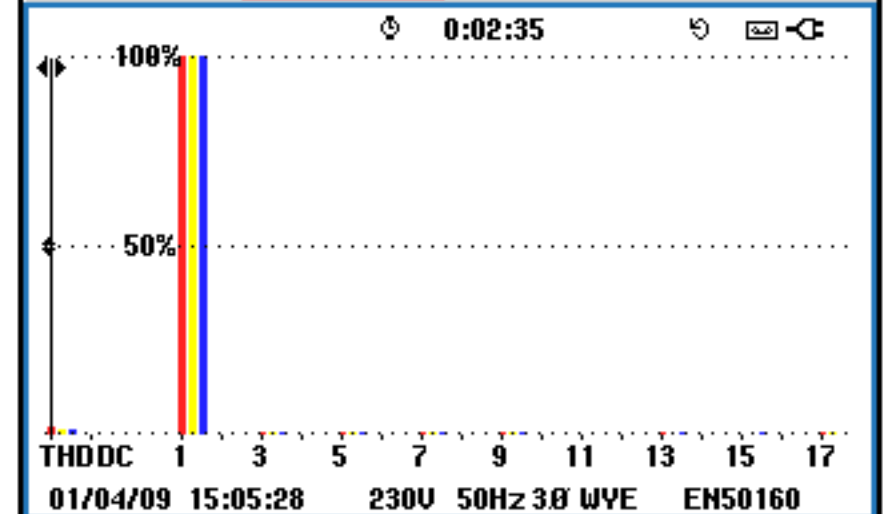 & 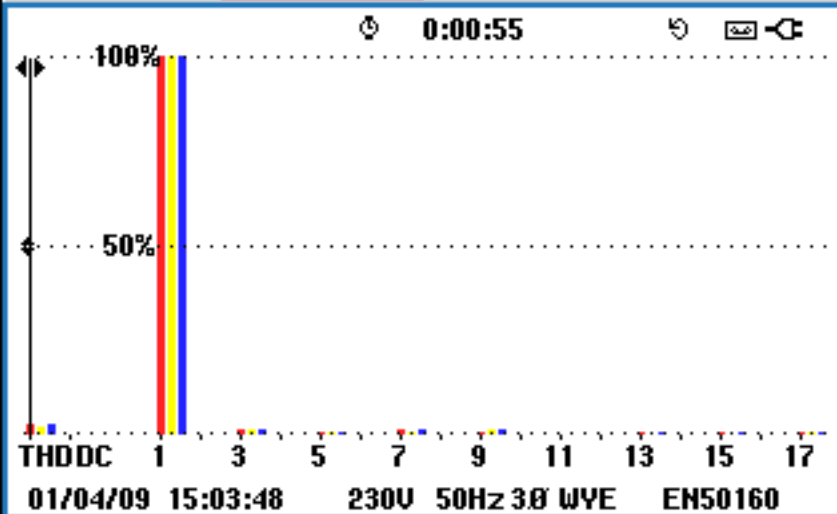 \\
\hline 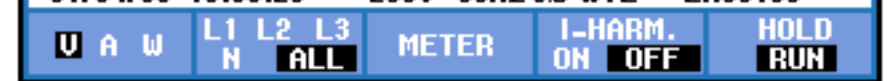 &  \\
\hline $\begin{array}{c}\text { (e) } T H D_{v}=1.8 \% \text { of the fundamental with the Active } \\
\text { Harmonic Conditioner ON }\end{array}$ & $\begin{array}{l}\text { (f) } T H D_{v}=2.5 \% \text { of the fundamental with the Active } \\
\text { Harmonic Conditioner OFF }\end{array}$ \\
\hline 4: Result of $T H D_{y}$ at SBE03 Incoming & $\mathrm{h}$ Active Harmonic Conditioner is ON and OFF \\
\hline
\end{tabular}

